\title{
Projeto individual de amplificação sonora
}

\author{
Marcelo A. Duarte (UniCarioca) \\ Giovani L. da Silva (UniCarioca) \\ Michele C. I. da S. Sobral (UniCarioca)
}

\section{Resumo}

O ouvido humano é incrivelmente sensível a uma grande variedade de atividades acústicas, as quais são processadas através do próprio ouvido, do sistema nervoso e do cérebro, e entendidas como sons. As próteses auditivas, em geral, amplificam todos os sons presentes no ambiente, permitindo que o portador de deficiência auditiva utilize a audição remanescente de modo efetivo. $\mathrm{O}$ aparelho apresentado neste trabalho consiste de um sistema de comunicação sem fio entre um transmissor e um receptor, de forma a permitir que a voz do locutor (professor) seja captada pelo aluno, eliminando a interferência dos ruídos do ambiente e melhorando o aprendizado do aluno, propiciando maior concentração e eficiência no rendimento educacional. O aparelho projetado é de baixo custo, podendo substituir os aparelhos importados construídos para esse mesmo fim.

Palavras-Chave: Deficiência auditiva, Aparelho auditivo, Sistema de RF.

\begin{abstract}
The human ear is incredibly sensitive to a wide variety of acoustic activities, which are processed through the ear itself, the nervous system and the brain, and understood as sounds. Hearing aids, in general, amplify all the sounds present in the environment, allowing the hearing impaired to use the remaining hearing effectively. The device presented in this work consists of a wireless communication system between a transmitter and a receiver, in order to allow the voice of the speaker (teacher) to be captured by the student, eliminating the interference of ambient noise and improving student learning, providing greater concentration and efficiency in educational performance. The designed device is low cost, and is able to replace the imported devices, built for this same purpose.
\end{abstract}

Keywords: Hearing Impairment, Hearing Aid, RF System.

\section{Introdução}

A deficiência auditiva, vulgarmente conhecida como surdez, consiste na perda parcial ou total da capacidade de ouvir. É considerado surdo todo individuo cuja audição não é funcional no dia-a-dia, e parcialmente surdo é aquele cuja capacidade de ouvir, ainda que deficiente, é funcional, com ou sem prótese auditiva.

Um aparelho auditivo tem a finalidade de ajudar as pessoas com perda auditiva a perceberem os sons. Os aparelhos auditivos melhoram a compreensão da fala em várias situações e dão suporte às muitas funções do sistema auditivo humano, como a localização sonora, compreensão, etc. As próteses auditivas, em geral, amplificam todos os sons presentes no ambiente, permitindo que o deficiente utilize a audição remanescente de modo efetivo. 
Lugares com muito ruído ambiente e a distância da fonte sonora podem dificultar a clareza no ouvir. Essa situação é representada pelo ambiente de uma sala de aula, pois esta costuma apresentar esses dois problemas básicos, ou seja, em geral apresenta ruído de fundo e certa distância entre o professor e o aluno. O ruído de fundo normal de uma sala de aula pode gerar desconforto e dificuldade de compreensão. A distância entre o interlocutor e o ouvinte também agrava esse problema, já que quanto maior for a distância entre esses dois, menor será o volume de voz do professor que chega ao ouvido do aluno.

O projeto em questão não trata da construção de uma nova prótese auditiva, mas sim de um sistema capaz de aumentar a concentração de alunos surdos durante as suas aulas. Trata-se de um projeto que inclui um transmissor e um receptor de FM, além de circuitos de ajustes de som, tais como um pré-amplificador, um equalizador e um amplificador de potência de áudio. A intenção é a de que a voz do professor seja transmitida pelo circuito transmissor diretamente até o circuito receptor, via ondas eletromagnéticas. O sinal (voz) será pré-amplificado e equalizado, antes de ganhar a potência necessária para que seja ouvido adequadamente por um aluno com deficiência auditiva.

O projeto foi inspirado no trabalho de Silva et al. (2007), denominado Dispositivo Auricular para Deficientes Auditivos (D.A.D.A.), já desenvolvido com a intenção de substituir aparelhos importados e caros, que possuem a mesma finalidade. O projeto de Silva et al. (2007) teve êxito na questão da transmissão e da recepção, mas é falho quanto ao tratamento do sinal recebido. Além disso, sua aplicação não abrange uma faixa ampla de deficiência auditiva, atendendo apenas aos portadores de deficiência moderada, uma vez que seu ganho de potência não é alto o suficiente para atingir níveis mais profundos de deficiência auditiva. $\mathrm{O}$ aparelho desenvolvido em 2007 é monofônico, ainda de grandes dimensões (35 cm x $30 \mathrm{~cm}$ ) e a autonomia de sua bateria é baixa (em torno de 5 horas).

Por esses motivos, este projeto foi focado na reconstrução adequada dos circuitos pré-amplificador, equalizador e amplificador de áudio, propostos inicialmente no projeto de Silva et al. (2007). Usando-se o receptor e o transmissor construídos por Silva et al. (2007), em conjunto com os novos circuitos projetados, conseguiu-se montar um circuito de fácil manuseio, capaz de atender a pessoas com perdas auditivas desde leves até severas, com maior autonomia (em torno de 10 horas), satisfazendo aos usuários em termos de qualidade sonora, com um baixo custo.

\section{Fundamentos Teóricos}

O ouvido consiste em três partes básicas: o ouvido externo ou orelha, o ouvido médio e o ouvido interno, como mostra a Figura 1. O ouvido externo é composto por duas partes: o pavilhão auditivo e o conduto auditivo externo (ou meato acústico externo). Serve para coletar o som e o levar, por um canal, ao ouvido médio. O ouvido médio (composto pelos ossículos martelo, bigorna e estribo, e pela tuba auditiva ou trompa de Eustáquio) serve para transformar a energia de uma onda sonora em vibrações, transformando estas vibrações em ondas de compressão, levando-as ao ouvido interno. O ouvido interno contém um fluido que transforma a energia da onda de compressão em impulsos nervosos, que são transmitidos ao cérebro para a sua interpretação. É composto pela cóclea e pelo aparato vestibular. (BERTULANI, 2007).

Basicamente, a audição funciona da seguinte forma: o som propaga-se, produzindo ondas sonoras que se deslocam até atingir a orelha. O mecanismo da audição transforma estas ondas em sinais elétricos, que são transmitidas como mensagens, através do nervo auditivo para o cérebro, que, por fim, as interpreta. (BERTULANI, 2007). 


\section{Deficiência auditiva}

Também conhecida como hipoacusia ou surdez, a deficiência auditiva é a perda parcial ou total da audição. Esta pode ser de nascença (congênita) ou causada posteriormente (adquirida), por doenças. As principais causas da deficiência congênita são hereditariedade, viroses maternas (rubéola e sarampo, por exemplo), doenças tóxicas da gestante (sífilis, citomegalovírus, toxoplasmose) e a ingestão de medicamentos ototóxi$\cos$ (que lesam o nervo auditivo) durante a gravidez. A deficiência adquirida ocorre quando existe uma predisposição genética (otosclerose) por ocorrência de meningite, ingestão de remédios ototóxicos, exposição a sons impactantes (explosão) e viroses, por exemplo (SILVA et al. 2007).

O deficiente auditivo é classificado como surdo, quando sua audição não é funcional na vida comum, e como hipoacústico, quando sua audição, ainda que deficiente, é funcional, com ou sem prótese auditiva. O grau da perda auditiva é calculado em função da intensidade necessária para amplificar um som, de modo que este seja percebido pela pessoa com deficiência auditiva. Esta amplificação mede-se, habitualmente, em decibéis (FASTER, 2005).

Para um diagnóstico correto da deficiência auditiva, é preciso fazer uma exploração audiométrica do grau de perda, com relação ao espectro de frequência que varia entre $125 \mathrm{~Hz}$ a $4000 \mathrm{~Hz}$, já que são estas as frequências mais utilizadas na fala humana (CASANOVA, 1992)

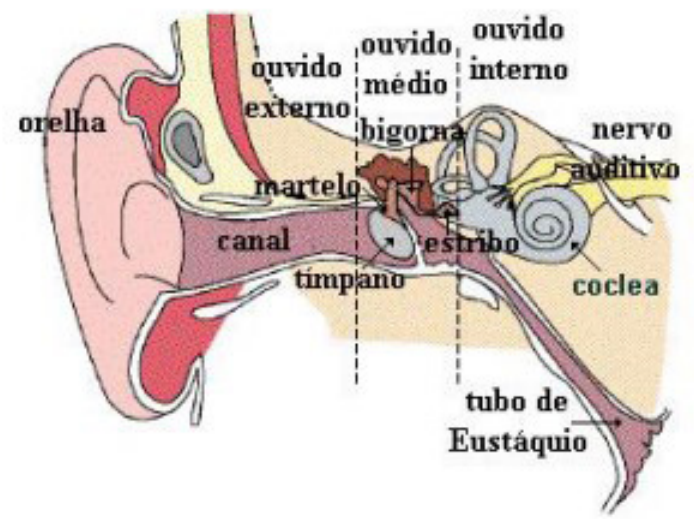

Figura 1: O ouvido humano

\section{O sistema FM americano}

Representado na Figura 2, o sistema FM (transmissor de FM/receptor de FM) funciona, basicamente, como um microfone sem fio, que transmite o som diretamente da boca do falante ao ouvido de quem deseja receber essa informação. O microfone (utilizado pela fonte sonora) capta o sinal desejado e o envia diretamente a um ou dois receptores (conectados ao aparelho auditivo). Com a amplificação adequada, o resultado é uma conexão clara e direta entre a fonte sonora e quem usa o aparelho. A voz é transmitida diretamente ao receptor, transmitindo a sensação de proximidade entre quem está falando e o ouvinte, sem a interferência do ruído de fundo e sem a diminuição do volume causada pela distância. O uso desse aparelho no ambiente de uma sala de aula traz enormes benefícios aos estudantes com problemas auditivos (SILVA et al., 2007). Esse sistema é fabricado e comercializado nos Estados Unidos, a um preço aproximado de três mil reais. 


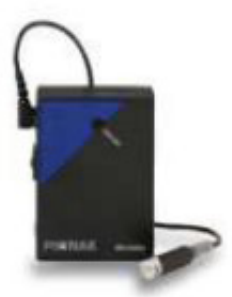

(a)

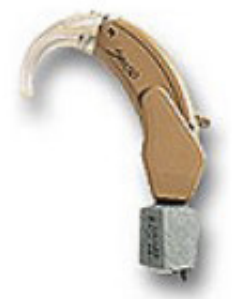

(b)

Figura 2: Sistema FM auditivo: (a) transmissor; (b) receptor

\section{O projeto}

Para cada estágio, circuitos foram montados e testados em protoboard, para que se pudesse definir o que melhor atendesse aos requisitos do projeto. Os circuitos escolhidos para compor o Projeto Individual de Amplificação Sonora (P.I.A.S.) encontram-se descritos a seguir. A Figura 3 ilustra o seu diagrama em blocos. Vale lembrar que, por estarem funcionando adequadamente, foram usados, para compor o P.I.A.S., o mesmo transmissor e o mesmo receptor usados no projeto de Silva et al. (2007).

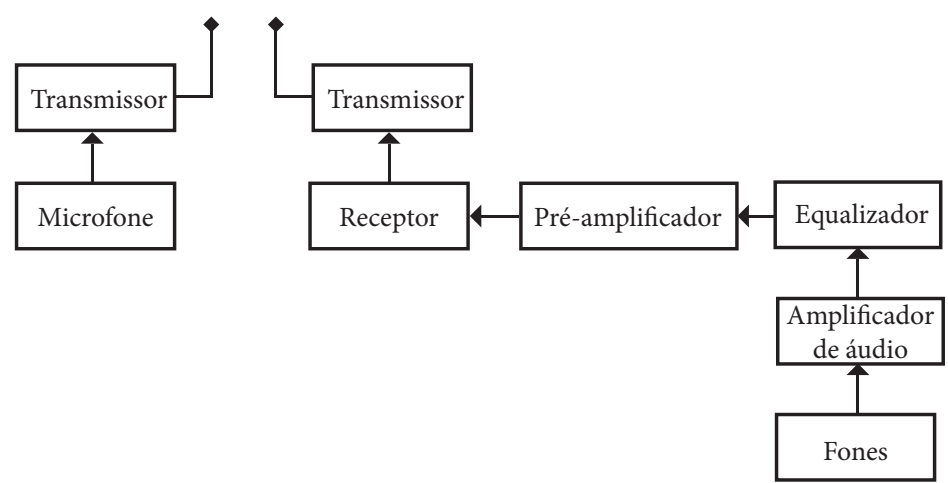

Figura 3: Diagrama em blocos do projeto P.I.A.S.

\section{Pré-amplificador}

Para o pré-amplificador, foi escolhido um circuito usando o transistor BC549, descrito por Braga (2010), com algumas adaptações, que apresentou alto ganho, sem distorção. Sua alimentação (Figura 4, já com as adaptações) é feita através de uma bateria de 9V. Como a corrente exigida é muito baixa, a durabilidade da bateria é grande. O nível de sinal de saída depende do nível do sinal de entrada e da amplificação. No caso, esta amplificação é da ordem de 50 vezes, mas pode ser alterada. O potenciômetro (ou trimpot) P1 permite que se ajuste o ganho do circuito para a fonte de sinal (microfone de eletreto) de modo a se obter uma saída sem distorção, capaz de excitar o equalizador e o amplificador de áudio. 
O circuito de Braga (2010) foi modificado em função da diferença de impedâncias entre a cápsula do microfone de eletreto e a entrada do circuito. Foi necessária a inclusão de um resistor de $1 \mathrm{M} \Omega(\mathrm{R} 5)$ entre a cápsula e o terminal positivo da bateria, para que houvesse melhor acoplamento do sinal de entrada no circuito pré-amplificador. Além disso, foi inserida uma segunda saída (C5 e J3), em paralelo com a que já existia (C3 e J2), para possibilitar equalizações diferentes em dois canais de saída, uma para cada ouvido do usuário, uma vez que as necessidades de cada ouvido, nem sempre serão iguais.

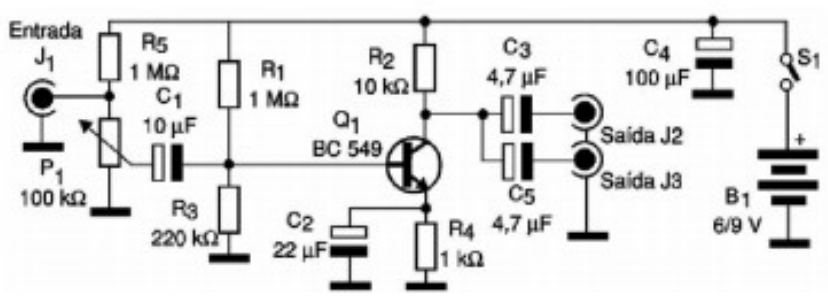

Figura 4: Circuito do pré-amplificador de áudio, adaptado a partir do circuito de Braga (2010).

\section{Equalizador}

O equalizador deve permitir o ajuste conforme as necessidades específicas do paciente. Partindo-se do princípio de que a deficiência auditiva pode afetar diferentemente cada ouvido, optou-se por construir um circuito equalizador que possuísse dois canais de saídas, ajustados separadamente. Para atender a esse requisito, o circuito equalizador encontrado no manual do CI BA 3822LS (Rohm, 2012), mostrado na Figura 5 , foi o escolhido.

O BA3822LS possui dois canais de saídas, e o equalizador construído a partir desse CI possui cinco frequências centrais: baixa $(100 \mathrm{~Hz})$, média-baixa $(330 \mathrm{~Hz})$, média $(1 \mathrm{kHz})$, média-alta $(3.3 \mathrm{kHz})$ e alta $(10 \mathrm{kHz})$ para cada canal. Este CI também pôde ser alimentado com a bateria de 9V, outro fator determinante para que fosse escolhido. Além disso, o BA3822LS é formado por 10 amplificadores operacionais, o que facilitou a montagem do circuito e permitiu reduzir o espaço utilizado no projeto.

Vale citar que, após a montagem da placa, ao ligar a fonte de alimentação com 9V para os testes, o sinal sofreu alteração por ruído, não sendo possível visualizar o sinal de saída no osciloscópio. Para eliminar esse ruído, foi necessário inserir um capacitor cerâmico de $220 \mathrm{nF}$ em cada entrada do equalizador para atuar como filtro. Além dessa alteração, foram retirados os capacitores de $4,7 \mu \mathrm{F}$ na entrada de cada canal, pois esse componente já existe na saída do circuito pré-amplificador, mostrado na Figura 4. 


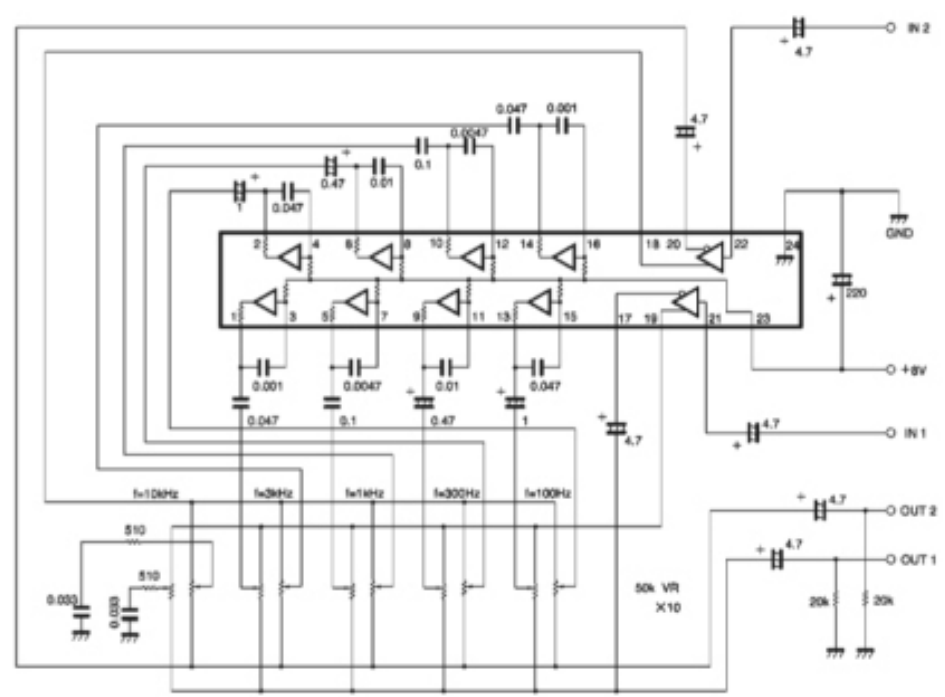

Figura 5: Circuito equalizador, descrito no manual do CI BA 3822LS (Rohm, 2012).

\section{Amplificador de áudio}

O circuito integrado LM386 foi escolhido como cerne do circuito amplificador de áudio, por possuir baixo consumo $(24 \mathrm{~mW}$ em $9 \mathrm{~V})$, por possibilitar sua alimentação (também com $9 \mathrm{~V}$ ) e por possuir circuito de fácil implementação, com alto ganho de potência. Foram usados dois circuitos amplificadores, sendo um para cada canal de saída.

O circuito usado como amplificador de áudio é mostrado na Figura 6 e foi implementado a partir do manual do fabricante do CI (SANTIAGO, 2012).

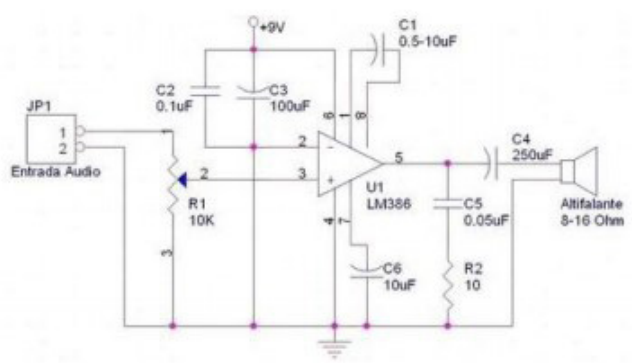

Figura 6: Amplificador de áudio, implementado a partir do manual do fabricante do CI LM 386 (Santiago, 2012). 


\section{Testes Práticos}

Quanto ao conjunto de circuitos (pré-amplificador, equalizador e amplificador), foram realizados vários testes práticos, a fim de se obter o ganho de tensão e de potência e a curva de resposta em frequência do equipamento.

O ganho médio de tensão obtido foi de $71,89 \mathrm{~dB}$, e o ganho médio de potência foi de $89,67 \mathrm{~dB}$. A Figura 7 mostra a resposta em frequência do P.I.A.S.

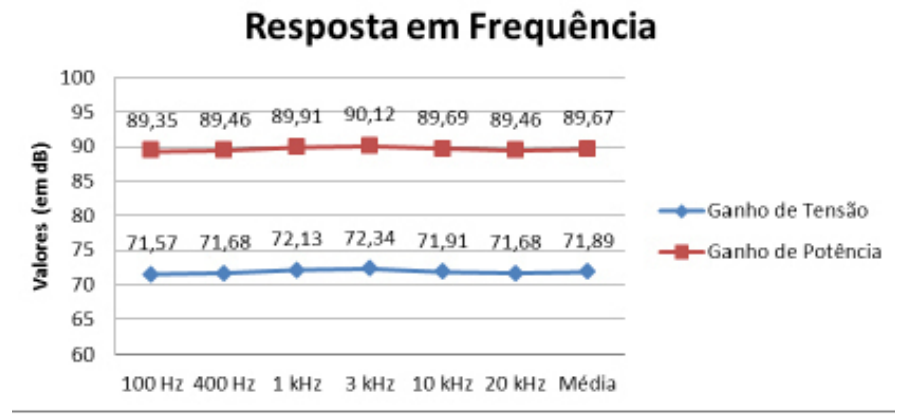

Figura 7: Resposta em frequência do P.I.A.S.

Aperfeiçoamentos alcançados em relação ao projeto de Silva et al. (2007)

O custo do equipamento foi de $\mathrm{R} \$ 62,58$, considerando apenas os materiais e componentes utilizados. O custo mostrado não inclui mão de obra, mas permite ter uma ideia do valor necessário para a construção do equipamento. Considerando o custo do transmissor e do receptor usados no circuito D.A.D.A. de Silva et al. (2007), que foram utilizados também no P.I.A.S., o custo subiria para R \$ 80,58. Observa-se que esse valor é $26,7 \%$ menor do que o valor gasto na confecção do projeto D.A.D.A. (aproximadamente, R\$ 110,00 ) e muito menor do que o custo total do projeto americano ( $\mathrm{R} \$ 3.000,00$ ). Ainda que não se tenha orçado formalmente o custo da mão de obra na fabricação do P.I.A.S., estimou-se, na época de sua execução, um custo de R\$10,00, por peça, na montagem de 200 produtos, o que certamente, garantiria um custo bem menor do que o produto americano. O circuito proposto nesse trabalho possui ainda as vantagens organizadas na Tabela 1, a seguir, em relação ao projeto D.A.D.A.

\begin{tabular}{|c|c|c|}
\hline Parâmetros & D.A.D.A & P.I.A.S \\
\hline Nivel de surdez atendido & Moderado & Severa \\
\hline Faixa de frequências do equalizador & 4 & 2 \\
\hline Canais de saída & 1 & $72 \mathrm{~dB}$ \\
\hline Ajuste do equalizador & Único para os 2 ouvidos & Individual para cada ouvido \\
\hline Ganho de tensão & $15 \mathrm{dE}$ & $90 \mathrm{~dB}$ \\
\hline Ganho de potência & $50 \mathrm{~dB}$ & $10 \mathrm{~h}$ \\
\hline Autonomia de uso & $5 \mathrm{~h}$ & $13 \mathrm{~cm} \times 13 \mathrm{~cm}$ \\
\hline Dimensões & $35 \mathrm{~cm} \times 30 \mathrm{~cm}$ & $\mathrm{R} \$ 80,58$ \\
\hline Custo total & $\mathrm{R} \$ 109,89$ & 59 \\
\hline
\end{tabular}

Tabela 1: Comparação entre os projetos D.A.D.A. e P.I.A.S. 


\section{Conclusões}

Em relação aos objetivos iniciais deste projeto, pôde-se observar que estes foram totalmente atendidos, uma vez que o projeto tem dimensões que permitem a construção de um aparelho discreto, com baixo custo. Além disso, a principal melhoria alcançada pelo projeto, em relação ao projeto D.A.D.A. (Silva et al., 2007), diz respeito ao ganho de potência de saída $(90 \mathrm{~dB}$ contra $50 \mathrm{~dB})$, o que possibilita atender às necessidades de um portador de deficiência auditiva até o nível de surdez severa, cuja faixa vai de 71 a $90 \mathrm{~dB}$.

Outra vantagem significativa do projeto, em relação ao D.A.D.A., está na utilização de um equalizador com 5 faixas de frequências, com dois canais de saídas, o que permite o ajuste para cada ouvido, separadamente, ampliando sua utilização para deficientes com diferentes níveis de perda auditiva em cada ouvido.

Vale citar, também, o aumento da autonomia de funcionamento do equipamento, que foi dobrada em relação ao projeto D.A.D.A.

O projeto ainda pode ser melhorado em suas dimensões, com o uso de componentes de tecnologia de montagem superficial (Surface-Mount Technology - SMD), e no aspecto da qualidade do som, com o uso de tecnologia digital.

A construção desse aparelho prova que, por mais difícil que seja a competição com as grandes empresas do mercado internacional, é fundamental investir em pesquisas para o desenvolvimento de aparelhos auditivos de fabricação nacional, com qualidade e custos que permitam o acesso de toda a população que sofra com algum tipo de perda auditiva.

\section{Contato dos autores}

Marcelo A. Duarte | mduarte@unicarioca.edu.br

\section{Referências Bilbiográficas}

BERTULANI, C. A. O ouvido humano. Ensino de Física a Distância. Material para uso didático - Instituto de Física, Universidade Federal do Rio de Janeiro, 2007. Disponível em: <http://www.if.ufrj.br/teaching/fis2/ondas2/ouvido/ouvido.html>. 11/04/ 2012.

BRAGA, N. C. Pré-amplificador de áudio, 2010. Disponível em: <http://www. sabereletronica.com. br/secoes/leitura/287>, 01/09/2012.

CASANOVA, P. Manual de fonoaudiologia. Porto Alegre, Artes Médicas, 1992. 386p.

FASTER. Deficiência Auditiva, 2005. Disponível em: <http://www.crfaster.com.br/ auditiv.htm>, 22/03/ 2012.

ROHM. Manual do CI BA3822, 2012. Disponível em: <http://www. datasheetcatalog.com/datasheets_pdf/B/A/3/8/BA3822LS.sht$\mathrm{ml}>, 03 / 10 / 2012$.

SANTIAGO, R. B. O Circuito Integrado LM386, 2012. Disponível em: <http://www. quartzo.net/eletronica/artigos/lm386/lm386. html $>, 01 / 09 / 2012$.

SILVA, D.; AFONSO, J.; DIAS, S. D.A.D.A. - Dispositivo auricular para Deficiente Auditivo, 2007. Trabalho de Conclusão de Curso (Engenharia Elétrica/Telecomunicações) - Departamento de Educação, Universidade Gama Filho, Rio de Janeiro. 